\title{
LA OBRA COMO PRODIGIO: EL EJERCICIO HERMENÉUTICO EN MIGUEL ÁNGEL ASTURIAS, CASI NOVELA DE LUIS CARDOZA Y ARAGÓN
}

\author{
Francisco Rodríguez Cascante
}

\begin{abstract}
RESUMEN
En este artículo estudio la concepción estético-biográfica del escritor guatemalteco Luis Cardoza y Aragón (1901-1992) planteada en su ensayo Miguel Ángel Asturias, casi novela (1991). Esta aproximación tiene como objetivo analizar los presupuestos teóricos del ejercicio interpretativo en el autor. El trabajo se organiza en tres apartados: primero dirijo mi atención a la propuesta estética. Posteriormente, comento la posición del autor relativa al ejercicio hermenéutico; y en último lugar, me refiero a la lectura que de Asturias realiza Cardoza y Aragón. Sostengo como hipótesis que el trabajo interpretativo ejercido por el escritor centroamericano se fundamenta en una concepción estética de carácter aurático-platónica anclada en los paradigmas totalizantes de la modernidad. Asimismo, argumento que este modelo artístico, dirigido a Miguel Ángel Asturias, privilegia el ámbito del biografismo impresionista elaborando un acercamiento ambiguo que al censurar al biografiado automodeliza moralmente al enunciador por su inscripción en el metarrelato socialista.
\end{abstract}

Palabras clave: Luis Cardoza y Aragón, Miguel Ángel Asturias, casi novela, ensayo, estética.

\begin{abstract}
This article studies the aesthetic-biographical conception of the Guatemalan writer Luis Cardoza y Aragón (1901-1992) raised on his writing Miguel Angel Asturias, almost a novel (1991). This approach has as an objective to analyze the theoretical presuppositions of the interpretive exercise of the author. The work is organized in three sections. First, I direct my attention to the aesthetic proposition. Later, I comment on the position of the author relative to the "hermeneutic exercise", and finally, I will talk about the analysis that Cardoza y Aragón makes of Asturias. I maintain the hypothesis that the interpretive work offered by the Central American writer is based on an aesthetic conception of an "auratic-platonic" character totally anchored in paradigms of modernity. Futhermore, I argue that this artistic model directed to Miguel Angel Asturias, allows the scope of the biographical impression elaborating an ambiguous approach that censures the biography "moulds" morally to the author by his inscription to the socialist "metarrelato".
\end{abstract}

Key words: Luis Cardoza y Aragón, Miguel Angel Asturias, almost a novel, essay, aesthetic.

Francisco Rodríguez Cascante. Profesor de la Sede de Occidente, Universidad de Costa Rica. San Ramón, Alajuela, Costa Rica.

Correo electrónico: rodriguezcascante@yahoo.com 


\section{Introducción}

La aparición en 1991 del último libro que publicó en vida Cardoza y Aragón, Miguel Ángel Asturias, casi novela ${ }^{1}$, generó una controversia que sigue vigente. La crítica está dividida en dos posiciones antagónicas: por un lado, los que defienden la idea de que se trata de un justo homenaje a Asturias; mientras, por el otro lado, varios críticos estiman que en vez de un homenaje es un violento ataque que procura descalificar al autor de El señor Presidente.

En la primera perspectiva, Jaime Labastida menciona que Cardoza supo diferenciar entre el hombre Asturias y el escritor Asturias, pero esta separación no fue hecha para perjudicar a alguno de los dos, sino para unirlos en un bloque que diera la imagen real del escritor ${ }^{2}$. Asimismo, insistiendo en la valoración positiva, Franz Galich opina que

no fue una 'ocurrencia' de última hora, senecta ocurrencia para desprestigiar al Nobel de Literatura de 1967. Puede decirse que este libro tiene similitud con Edipo en Colono, tanto por su contenido como por lo que motivó su escritura. Con el libro de Cardoza, Asturias asciende hasta el lugar donde debe estar, raptado por lo tempestuoso de la voz cardociana (1995: 28).

Para otros críticos, el trabajo final de Cardoza es una arremetida envidiosa que procura degradar a Asturias señalándolo como traidor de las causas indígenas y aliado de los dictadores. Afirma Mario Payeras que

no es éste un libro afortunado y contrasta con otros de Luis Cardoza. Dos veces lo leí, esperando modifi-
car mi primera impresión desfavorable, pero confirmo el juicio original. Es en mi opinión un libro dog-
mático como estética, lo hallo pletórico de las pretensiones de todo vanguardismo y lo siento ajeno sobre
todo a la cultura democrática que Guatemala reclama con apremio (1992: 57).

Dante Liano, por su parte, resalta aciertos y desaciertos de la crítica hacia Asturias, pero enfatiza en que son tantos los aspectos negativos que destaca Cardoza que sus alabanzas a su compatriota resultan inverosímiles:

\footnotetext{
La impresión que se recaba de tales afirmaciones no es la de la búsqueda de la verdad a toda costa, como el autor cree. Se tiene, en cambio, la imagen de una poco generosa ambigüedad. Cada altísimo halago, cada diploma de genialidad expedido por Cardoza son descalificados por una carga de profundidad biográfica o política que arrastran al novelista guatemalteco al fondo de la iniquidad (1997: 187).
}

El ensayo se sitúa en la perspectiva cardociana de abordar personajes de la cultura letrada y construir un boceto de ellos destacando sus contradicciones, tal como lo vino haciendo desde Guatemala, las líneas de su mano hasta El río, novelas de caballería. Sin embargo, Asturias es el autor al que nunca se había aproximado y, debido a la importancia de su producción, la cual problematiza múltiples aspectos identitarios de Guatemala, señala que "mi galería de esbozos de escritores guatemaltecos estaba trunca sin Miguel Ángel Asturias, 'mi paisano inevitable"" (1991: 9), recuperando la frase con la que Coronel Urtecho se refería a Darío ${ }^{3}$.

La importancia de este último libro de Cardoza radica, en primer lugar, en que no solamente se acerca al novelista guatemalteco más legitimado de su historia literaria, sino que plantea una preceptiva de crítica literaria con base en su concepción de la estética, construyendo a lo largo del texto un marco teórico que sigue letra a letra. En segundo lugar, a partir de estas concepciones comenta la producción de Asturias y establece su valoración de la producción textual del Premio Nobel. 
En las líneas que siguen, analizo los aspectos recién indicados. Primero, dirijo mi atención a la propuesta estética cardociana, la que es importante porque permite entender su valoración de la producción literaria y de la figura de Miguel Ángel Asturias. Posteriormente, comento la posición del autor relativa al ejercicio interpretativo y, en último lugar, me refiero a la lectura que de los textos asturianos realiza Cardoza y Aragón.

\section{Del esencialismo estético al biografísmo crítico: la obra como prodigio}

En este ensayo, Cardoza elabora una perspectiva de comprensión que lo conduce a cuestionar tanto la figura biográfica de Asturias como su producción literaria. Este conjunto de ideas en Miguel Ángel Asturias, casi novela aparece esbozado con suma claridad y sus primeros elementos los constituyen una concepción platónica del arte y una noción de obra como producto excelso.

Miguel Ángel Asturias, casi novela parte del supuesto de la existencia de "una cultura universal" con cuyos cánones debe dialogar cualquier producción artística. Esta concepción esencialista dicta una norma de valor general y constituye, también, el elemento que censura cuándo se está en presencia de un objeto artístico: "La poesía no quiere ser. Es" (1991: 21). ¿Cuándo es un objeto arte?, ¿qué elementos debe poseer para ingresar al mundo estético? En el ideario cardociano esta cualidad se presenta cuando el objeto es capaz de impresionar positivamente a su enunciatario: "Una obra de arte nos deslumbra, nos asciende a una situación de éxtasis" (1991: 45), dejando de lado cualquier tipo de consideración ideológica o moral, es decir, apartando el posible "contenido" o "mensaje" del texto, puesto que "son inválidos los juicios éticos y los juicios ideológicos emitidos sobre los valores estéticos” (1991: 63).

El arte, en este sentido, debe poseer aquella dimensión aurática que, explicaba Benjamín, era parte de la concepción moderna del arte 4 , la que le otorgaba carácter de "obra" al elemento artístico, al igual que otros calificativos como autenticidad y elevación, acercándolo a una solemnidad de tipo religioso; aspectos todos ellos que entran en crisis gracias a la reproducción tecnológica implementada en la era moderna ${ }^{5}$. Esta idea de la obra, cuyas particularidades y diferencias respecto al texto planteaba Barthes ${ }^{6}$ en 1971, es asumida por el enunciador de Miguel Ángel Asturias, casi novela en forma categórica: la "obra" deviene magia y elevación superior a la realidad cotidiana. Cuando expone su recuerdo de cómo un albañil, en una visita a la colección de óleos de L'Ermitage que se exhibió en México en 1976, apreció un Rembrandt, describe el interés del observador como un acto de comunión y queda desarmado para comentar la exposición: "más valía el rapto del albañil que cualquiera explicación de mi parte. ¿Qué palabras sabría decirle el más docto al embebecido por el prodigio?” (1991: 165).

En esta perspectiva no tiene sentido preguntarse por los procesos de producción artística ni tampoco cabe mayor explicación de ellos, porque "el proceso de la creación es cósmicamente misterioso" (1991: 22) e igualmente, "escribir es misterio" (1991: 179) que sólo es accesible al "creador" cuando es poseído y transportado a un místico espacio irracional y luminoso que posee claras resonancias platónicas?:

Aquello que está más allá, fuera de los confines de la racionalidad y de la lógica, eso irracional que se aproxima a lo que se intuye al otro lado: animales que somos, por instantes disfrutamos de iluminaciones y nos despojamos de mortalidad. Esos instantes son los que constituyen la luz de un artista, si consigue una vislumbre de lo que late al otro lado. La comunión con este sentimiento ha sido a la par agobiante y vivificador (1991: 181). 
De esta noción de obra, desprende Cardoza una composición binarista: se remite a la tradicional división entre forma y contenido, privilegiando la primera sobre la segunda: "La Forma, metidos hasta los hombros en la realidad, es la que eleva la creación, la que otorga eminencia y la inviste de lo sublime. Las ideas (las que sean) no destruyen ni penumbran la Forma. La Forma es destruida por la indigencia de los valores intrínsecos" (1991: 32). Es gracias a esta relación asimétrica que la obra adquiere autonomía como objeto estético, categoría que caracteriza la estética de la modernidad ${ }^{8}$. Refiriéndose a Hombres de maíz, apunta como su elemento más importante dicha autonomía en tanto objeto estético: "es epítome de su creación, donde lo que nos importa es otra realidad, peripecias y personajes paradigmáticos que mejor nos embelesan cuanto más viven en el clima sonambúlico que ha de ser suyo, cuanto son más inverosímiles y milagrosos" (1991: 80).

La categoría de obra conlleva otro criterio más: debe sorprender, requisito indispensable que el enunciador exige y que se convirtió en parte fundamental de la concepción estética cardociana desde su estadía en Francia en la década de los veinte y su relación con las vanguardias, especialmente con el surrealismo: "Acerquémonos a lo tempestuoso, a lo desgarrador, a lo bello y auténtico y reconozcamos la legitimidad" (1991: 165). Recuérdese que los movimientos de vanguardia constituyeron modelos de modernidad para muchos autores latinoamericanos de la primera parte del siglo XX, quienes veían en Europa y Estados Unidos la norma literaria y cultural, frente a un regionalismo que no les llenaba sus ansias de "universalidad".

El propósito de las vanguardias, indica Andreas Huyssen, era construir "un arte nuevo en una sociedad diferente" (1989: 269), cuya finalidad consistía en atacar el arte burgués. Esta poética, señalaba Huyssen en 1981, no solamente "se ha convertido ella misma en tradición, sino que, además, sus invenciones e imaginación se han convertido en parte constitutiva incluso de las manifestaciones más oficiales de la cultura occidental" (1998: 142). Es por estas razones que García Canclini afirma que las vanguardias "hoy son vistas como la forma paradigmática de la modernidad" (1990: 42) debido a que extremaron la búsqueda de la autonomía en el arte 9 . Para Cardoza, ser moderno implicaba abandonar el regionalismo, por localista y "pintoresco", para producir una literatura lo más alejada posible del realismo, la que debía dialogar con los cánones estéticos legitimados por los centros de modernización internacional. Así, los principios renovadores de las vanguardias se convirtieron para él tanto en sinónimo de norma literaria como de modernidad cultural.

La novedad en tanto herencia de las vanguardias y búsqueda de la libertad imaginativa ha estado presente en la producción literaria y crítica de Cardoza desde la publicación de su primer libro: Luna Park (1924), en el que ya se evidenciaba el esfuerzo por construir un lenguaje pleno de imágenes "tempestuosas". El primer poema del libro puede leerse hoy como una declaración de principios estéticos que se mantuvo hasta su último trabajo: "Y aeronauta ebrio de vértigo, / ¡Lancé mi lastre al pasado / Y me hice todo alas!” (1924: 21). Esta idea de la literatura como vértigo y sorpresa se puede observar, también, en el segundo libro del autor: Maelstrom (1926), en el que el personaje Keemby es definido como un sujeto que "careció de principios generales toda su vida y vivió sorprendido: fue un Poeta" (1926: 22). La misma estética está presente en los textos poéticos posteriores, por ejemplo en Pequeña sinfonía del nuevo mundo ${ }^{10}$ (1948), Dibujos de ciego ${ }^{11}$ (1969), Quinta estación ${ }^{12}$ (1972) y Lázaro ${ }^{13}(1994)$.

No sólo del programa vanguardista de Cardoza es importante señalar su origen, sino también de sus concepciones sobre estética, las cuales tienen su primera formulación teórica en un texto dedicado a las artes plásticas mexicanas: La nube y el reloj (Pintura mexicana 
contemporánea, 1940). Después de la publicación de dos libros dedicados a autores específicos: Carlos Mérida (1927) y Rufino Tamayo (1934), La nube y el reloj es un esfuerzo por ofrecer una síntesis crítica de la pintura mexicana contemporánea, donde, además de realizar una interpretación de diversos autores (Agustín Lazo, Carlos Mérida, Rufino Tamayo, Julio Castellanos, David Alfaro Siqueiros, Diego Rivera y José Clemente Orozco), plantea un arte poética en la parte introductoria que titula "Comentarios generales". En esta define el arte como "la suma total de los sentidos de la vida. No necesita ser ilustración de ninguna imagen particular de la vida. Su mismo interés vital está en relación directa con su perfección, ajeno a toda realidad circundante, independiente de ella" (1940: 27).

Así como la valoración de la vanguardia se mantiene como la esencia a partir de Luna Park, igualmente la autonomía estética planteada en La nube y el reloj se presenta en otro trabajo de carácter panorámico: Pintura contemporánea de México (1974), y en el ensayo objeto de estudio en este capítulo: "Una obra de arte nos deslumbra, nos asciende a una situación de éxtasis" (1991: 45). Magia, rapto, grandeza, trascendencia, prodigio son los términos que conceptúan El arte y La obra como creación en los escritos de Cardoza. Estos elementos, junto con otros más concretos como lo fantástico y la invención poética ${ }^{14}$, son los que le permiten concebir la existencia de un paradigma "universal" del arte al que el artista debe atenerse.

Cardoza defiende aquel tipo de creación que se apegue a criterios de libertad y calidad estética, además de privilegiar la ruptura y la sorpresa como marcadores de dicha poética. Consecuentemente, aquella producción que no se adscriba al modelo es sancionada y subvalorada. Esta poética nunca sistematizada por el autor es sumamente coherente con el proyecto modernizador que propone Cardoza. Para formar parte de la culturas modernas, el arte que debe seguirse como modelo es el "universal", cuyas "creaciones trascendentes" tenían que seguir los modelos culturales legitimados en tanto "universales": las producciones clásicas y modernas tanto americanas como europeas. Por eso forman parte destacada de sus referencias de autoridad las artes precolombinas, Orozco, Mérida, Baudelaire, Goethe, Montaigne, correspondientes a su idea del mestizaje como equilibrio entre las sangres indígena y española.

Por otra parte, la poética cardociana va más allá de las vanguardias. Aunque reconoce que "toda creación de una manera u otra tiene referencia o incide en su medio y su época" (1986: 756), en su concepción el arte no puede poseer barreras históricas: "La suprema finalidad de la poesía es el acto puro: crear el mundo perpetuamente" (1988: 230). Esta comprensión del arte condujo al autor a construir una literatura con una gran densidad formal y de amplia experimentación con las posibilidades semióticas del lenguaje, tal como lo explica Dante Liano:

\footnotetext{
Cardoza logra conciliar dos actitudes fundamentales: una rigurosa indagación del lenguaje, que lo convierte en un maestro del idioma, y un interés infatigable, casi sagrado, por las principales inquietudes humanas, lo que lo hace un poeta de aliento universal. A eso se debe la sobriedad de su producción. Cardoza es demasiado respetuoso del hombre y del lenguaje como para caer en las tentaciones de la retórica. Es en este sentido que se propone, junto con los grandes escritores del siglo, como una lección muy importante para las nuevas generaciones. De rigor, en primer lugar (1997: 179).
}

\section{El ejercicio hermenéutico}

Para la crítica literaria, reclama el enunciador de Miguel Ángel Asturias, casi novela la vigencia del biografismo: "Quiero precisar que en Asturias no aparto su vida de la escritura y 
voy de la obra a la vida y de la vida a la obra. Una vida no explica una obra, en algo la ilumina, en algo la oscurece" (1991: 17). Esta perspectiva adquiere gran densidad reflexiva y constituye la mayor parte del ensayo, que, además, contiene múltiples elementos autobiográficos de Cardoza, quien se compara frecuentemente con el novelista al que se aproxima. El enunciador se construye en tanto seguidor de las grandes mayorías sociales, frente a un Asturias indiferente; por ejemplo, en los pasajes referidos a la Revolución Guatemalteca de 1944, se presenta como agente de transformación y lucha, mientras que Asturias se propone indiferente y ajeno:

\begin{abstract}
En octubre de 1944 encontré a Miguel Ángel un poco grueso, quizás algo abotagado, decaído y harto. Quizás como lleno de desasosiegos y derrumbes y de lentas desesperaciones. Apartado lo mismo que un leproso. Como siempre lo encontré con sus bondadosas sonrisas irónicas, refranes y ocurrencias que en mi memoria lo ligaban a un ambiente de novela de nuestro Pepe Milla elevado al cubo; Milla nunca vio a un indio sino sólo el color local mestizo de la clase media. En mi camino a Guatemala iba henchido de nostalgia de México y de nostalgia de Guatemala, henchido de augurios y expectaciones. En una vuelta del camino súbito salta el Volcán de Agua y pensé con más ahínco en mi madre y hermanos. El único viejo amigo que ansiaba encontrar era Miguel Ángel, a quien abrazaría después de doce años. Imaginé que juntos emprenderíamos cosas hermosas. Ignoraba su situación de entonces (1991: 58).
\end{abstract}

No es, por otra parte, una crítica objetiva o analítica la que reclama el enunciador, sino creativa: "Para mí la subjetividad, tanto en la creación como en la crítica de ésta, ejerce imperio eminentísimo" (1991: 21). Los referentes de ésta no los constituye la tradición crítica ni la teoría literaria, sino el impresionismo y lo que el enunciador concibe como la "crítica de los poetas", oponiéndola a la crítica académica. De acuerdo con Méndez de Penedo:

\footnotetext{
Alla chiusura che percepisce nella critica accademica, egli oppone l'apertura della critica impressionista, perché considera che questa si concepisce e si esprime in libertà, senza la presunzione di giudizi inappellabili o definitivi. In altre parole, a un' arte sperimentale, con diverse letture epocali, dovrebbero corrispondere una compresione e una valutazione intuitiva più che razionale (2001: 167) .
}

En esta perspectiva, sus referentes críticos son Oscar Wilde, Sainte-Beuve, T.S. Eliot, Proust y Baudelaire. Para Méndez de Penedo, la mejor crítica es la que realizan los 'creadores': "Cuando he defendido la crítica de los poetas se debe a que en nada la creo impresionista. Creo que en el juicio emitido hay razones y sentimientos manifestados en sistemas abiertos de apreciación con escritura diferente. Un 'me gusta' o 'no me gusta' de Picasso venía de muy lejos" (1991: 164). Este impresionismo que el enunciador legitima de la poética de Baudelaire ${ }^{15}$ lo conduce, a la vez, a rechazar la teoría literaria contemporánea como sistema válido de interpretación porque procura eliminar la subjetividad y la creación en la apreciación de la obra, ese incognoscible "muy lejos" de Picasso: "La teoría literaria reduce el espacio del impresionismo crítico, el cual suele encerrar fatuidad" (1991: 164).

Con base en estos criterios, la escritura de la crítica no debe diferenciarse de la escritura poética: "No distingo, no diferencio la escritura de la crítica de la escritura de la poesía" (1991: 32), para lo cual "La exposición de la obra es otra obra que se mide con la obra que elucida" (32). Ya en Apolo y Coatlicue (1944) planteaba Cardoza que la crítica es un absurdo, un rodeo retórico que nunca va a llegar a la "esencia" del objeto artístico ${ }^{16}$. Tal negación de la crítica literaria objetiva se explica en el sistema cardociano porque dado el mundo "misterioso" que cobija el arte, en esa dimensión donde lo racional no tiene mayor espacio "lo aducido por el juicio poético ve más lejos que el juicio analítico" (1991: 197). 
En este sentido, tanto el arte como la crítica asumen la irracionalidad defendida también en El río, novelas de caballería, en tanto ámbitos que pueden interpretar mejor la complejidad de la existencia. Este reclamo del valor de lo irracional en el arte tiene que ver con la asunción de la dimensión aurática de la estética moderna. Por otra parte, su cuestionamiento a los programas de organización política y exclusión social del capitalismo asume la racionalidad sociológica al mismo tiempo que privilegia la utopía. Este movimiento dialéctico entre irracionalidad y racionalidad es la forma en que Cardoza asimila los metarrelatos modernos.

La justificación de la crítica biográfica se sustenta en el hecho de que la vida explica la "obra" y viceversa; además de que en el texto existen marcas de la subjetividad autoral (un "yo profundo"17) que se debe poner en comunicación con la subjetividad del comentarista: "El yo profundo de un artista de la palabra es tan misterioso que éste lo ignora. Quien indaga ese yo profundo inmiscuye su propio yo profundo" (1991: 82). Ese "yo profundo" únicamente es posible identificarlo mediante la aproximación biográfica, cuyas luces y sombras debe el analista intentar mostrar.

Esta perspectiva hermenéutica ${ }^{18}$, tan próxima a la estilística intuicionista de Dámaso Alonso $^{19}$, propone identificar en el texto el "reflejo" de la vida autoral mediante el descubrimiento de un estilo, entendido como "las huellas digitales del alma" (1991: 95), procurando dar cuenta, mediante un texto poético, de las luces y sombras de la subjetividad de quien escribió. Es por ello que la crítica cardociana intenta presentar los "claroscuros" de los autores, es decir, aspectos tanto positivos como negativos de ellos. Miguel Ángel Asturias, casi novela no es la excepción. En este texto el propósito del enunciador es construir un recuerdo "totalizador de Asturias, suma de luz y penumbra, donde ha de estar visto con cercanía su ser más íntimo" (1991: 12). El resultado de estas ideas son atisbos llenos de sugerencias, erudición y poesía, pero faltos de profundidad analítica.

\section{El asedio a Asturias}

El ensayo se dedica a plantear los claroscuros de Asturias; sin embargo, considero que se acentúa una fuerte descalificación a la figura personal y política de Asturias, mientras que su producción literaria es sometida a la valoración desde la concepción estética y crítica de Cardoza, la cual se orienta a estudiar un sólo texto: Hombres de maíz.

En cuanto a la dimensión biográfica de Asturias, el ensayo construye dos personajes: un Asturias y un Cardoza; el segundo constantemente se compara con el primero para destacar la "superioridad literaria" del primero, pero la mayor ética del segundo. El Cardoza autobiográfico elaborado en el texto se presenta como un gran amigo de Miguel Ángel Asturias, lo que le da la autoridad para juzgar la vida del novelista. Dicha amistad se inicia durante la estadía de ambos en París, período considerado como el único en que el Premio Nobel encontró la felicidad ${ }^{20}$. No obstante, tal declaración de amistad intensamente reiterada, incluyendo una sustitución del nombre de Asturias por "mi amigo" parece a lo largo del texto "más proclamada que sentida" (Liano 1997: 188), debido a la estrategia retórica del ensayo que, al intentar cumplir con su precepto de dar luces y sombras, introduce al lector en una desorientadora y sugerente ambigüedad.

El texto no desarrolla aspectos específicos y los concluye, sino que se construye con base en los recuerdos del enunciador, los cuales se entremezclan y se retoman más tarde. 
Como estrategias para crear la ambigüedad se presentan extensas series de preguntas que en sí mismas contienen cuestionamientos a Asturias, como: “¿Leo tragedia dolorida, 'íntima tristeza reaccionaria’, como diría López Velarde? ¿No era posible una conversión? ¿Logró ser lo que hizo? ¿Hizo lo que era? ¿Era lo que hizo? ¿Era lo que dijo?” (1991: 218). Otra estrategia importante es la autorreflexión que intenta convencer al lector de las bondades del procedimiento crítico: "En la digresión me guió el instinto, tanto como el razonamiento, harto de penumbras y subjetivismos; así puse sitio a la obra y al hombre y al personaje" (221). También está el esfuerzo por eliminar cualquier sospecha de parcialidad y mala voluntad: "Muy tonto sería que hubiese ignorado que de intentar en vano hundirlo, yo sería el hundido" (222); al igual que se propone como un abanderado de la objetividad, contradiciendo su defensa de la parcialidad: "No he basado mis observaciones en subjetividad alguna; las he basado en hechos y testimonios de hombres excelentes" (139).

Las declaraciones de dudas, de antidogmatismo y la presentación de "lo positivo" y "lo negativo" de Asturias son recursos que intentan convencer al lector de la claridad de una propuesta que no busca otra cosa más que "la verdad" del retrato que se construye como un intento de "totalidad" biográfica. Sin embargo, en esto el texto es contradictorio, ya que mientras afirma que "Repudio cualquier asomo de dogmatismo y dudo de mis certidumbres" (1991: 228), se previene contra cualquier lectura que dude de las buenas intenciones anticipándose al lector que no esté de acuerdo con las afirmaciones que sostiene: "nada más un hijo de puta pensaría que la obra desmerece o merece si evocamos al hombre Asturias en ciertos momentos de su vida" (220-1).

Estimo que la anunciada ambigüedad tiene el propósito de generar dudas sobre Asturias, ya que después de cualquier gran alabanza introduce el cuestionamiento y la censura: "Hay en Miguel Ángel real ternura para lo guatemalteco, ¿no así para los guatemaltecos?" (1991: 218). También ejemplo de esto es el recurso autobiográfico, donde se construye un sujeto autorreferencial moralmente superior al personaje Asturias. Esta insistente estrategia tiene la finalidad de plantear los recuerdos como hechos biográficos compartidos, conocimientos de primera mano dados por un testigo excepcional que en su amistad procuró siempre conducir y guiar a un amigo equivocado: "Una vez más intenté servirlo, quería que mi amigo fuese como sus páginas bellas" (1991: 203).

¿En qué consiste la censura a Asturias y a qué se debe? Ésta se presenta en dos planos: el personal y el político. En el primero, el enunciador alude a un supuesto alcoholismo y a un fanatismo religioso. A pesar de que luego afirma que la enfermedad se presentaba por períodos y que su religiosidad se debió al medio tan "atrasado" donde se formó, no deja de transcribir un sarcástico comentario que le dijo Flavio Herrera:

La última vez que vi a Moyas (nombre que le dábamos amistosamente) lo encontré vestido de 'cucurucho' en la última Semana Santa, durmiendo con su camisón morado, el cirio entre las piernas, en una banca del Parque de la Concordia. Eran como las doce de la mañana. Cuando le cerraron la cantina ya no pudo encaminarse a su casa (1991: 50).

A pesar de que afirma que Asturias poseía humor, lo presenta como un hombre egoísta, soberbio, violento y cerrado en sus juicios: "Hubo en él violencia contra lo que impugnaba su criterio" (1991: 158), al extremo de que acusó de plagio a García Márquez cuando éste publicó Cien años de soledad ${ }^{21}$. De nuevo la ambigüedad, esa desequilibrada presentación de luces y sombras, donde el personaje Asturias se torna cada vez más oscuro. 
Por otra parte, es interesante el relato autobiográfico relacionado con Rodrigo Asturias. El enunciador afirma que el hijo menor de Asturias, Miguel, lo visitó después de la muerte del novelista y le confesó que el autor lo odiaba porque creía que le había robado el cariño de Rodrigo, el hijo mayor y Comandante de la Organización del Pueblo en Armas (ORPA). En la construcción de Cardoza, su sujeto autorreferencial representa el valor de una vida moralmente comprometida con la justicia social: la revolución, el pueblo, la lucha contra las tiranías; de ahí sus exilios, mientras que Asturias es caracterizado por su sojuzgamiento y su indiferencia ante los gobiernos totalitarios. Como Rodrigo Asturias asumió la lucha guerrillera, Cardoza creyó haberse convertido en su modelo humano. Al intentar explicar el supuesto odio de Asturias se hace evidente la conflictiva visión del enunciador hacia el novelista: "mi pálida escritura no le molestaba, ¿tal vez mi vida?” (1991: 215) y agrega: “me transformaba de presunto envidioso en envidiado influyente? Me ha parecido una y otra vez que tal actitud sería impropia de su talento. ¿Cómo si yo hubiese visto el punto vulnerable de su armadura leniniana y nobelesca?" (207). Queda a la vista una de las motivaciones de la ambiguiedad: un posible resentimiento hacia los éxitos del Premio Lenin de la Paz (1965) y Premio Nobel de Literatura (1967), compensada en la narrativa del ensayo por la ejemplaridad de la vida del enunciador, supuestamente modelizada por el hijo y envidiada por el padre.

Pasando al plano político, el enunciador recuerda la tesis de abogado titulada El problema social del indio (1923), donde Asturias plantea las ideas de su época: que los indios son antihigiénicos, es raza degenerativa, decadente, inmoral. No obstante, luego indica que tal actitud es prontamente superada. También señala que el novelista no tuvo una formación política en su estancia en París ${ }^{22}$. Sin embargo, la observación más fuerte consiste en sugerir una posible simpatía por los dictadores y el poder: "Conjeturo de nuevo [...] que lo atraían los hombres fuertes, que los consideraba necesarios en nuestros pueblos analfabetos y como incapaces para el disfrute de la democracia" (1991: 229). La censura se dirige inicialmente al hecho de que Asturias trabajó en El Liberal Progresista entre 1934 y 1937, periódico del régimen ubiquista; también que formó parte de la Asamblea Constituyente, la cual fue integrada para la tercera reelección del dictador; a la vez que fue diputado durante el régimen ubiquista entre 1941 y 1944. El último reparo es que Asturias no firmó el "Memorial de los 311", donde los intelectuales pedían la destitución de Ubico.

Cuando el personaje Cardoza regresa a Guatemala en 1944 a integrarse a la Revolución, visita a Asturias y dice encontrarlo deprimido y sin ganas de involucrarse en los proyectos de renovación del país. El enunciador relata que los estudiantes lanzaron a Asturias en 1945 en la fuente de la Escuela de Derecho, en represalia por sus actitudes pro-dictadura y con ironía apunta que "reclamé a los estudiantes que lo veían como ku klux klan y no como Kukulcán” (1991: 92), y lo censura nuevamente: "aún no corregía su imagen” (92), haciendo evidente un relato donde un revolucionario procura orientar, sin éxito, a una oveja descarriada que, a pesar de que fue un genio de la literatura, estuvo equivocado en sus convicciones políticas.

Siguiendo la línea de críticas, por último, la censura se orienta al hecho de que Asturias aceptó ser embajador en París del gobierno de Julio César Méndez Montenegro en 1966, a pesar de que el enunciador intentó convencerlo de cambiar de opinión: "presumo, ahora, que le molestó mi anhelo de extirpar al hombre que sirvió a la dictadura y volviese a ser, por su amor a las letras, algo próximo al joven de los años en París" (1991: 158). Este proceso a Asturias, guiado por la concepción crítica que antes expuse, concluye con una severa 
sentencia, al alejarse el estudiado del modelo político que tiene como premisa el enunciador: "desde el punto de vista martiano, no fue un hombre de su tiempo o lo fue en la vertiente opuesta" (158).

Tales críticas a Asturias se deben, por supuesto, al hecho de que Cardoza defendió el socialismo como único paradigma de actuación política y, consecuentemente, rechazó de manera absoluta las dictaduras como sistemas de gobierno. En este sentido, él siempre observó una clara y coherente conducta política que lo mantuvo en el exilio, tal como lo plantea Dante Liano:

\begin{abstract}
Hay, en su vida y obra, una honestidad fundamental, ligada al incesante trabajo, a la incansable búsqueda intelectual, alejada de dogmatismo y falsas certezas, enemiga de pactos acomodaticios, ajena a la sumisión intelectual. Y, en segundo lugar, de entrega a su propio pueblo. La obra de Cardoza es el testimonio de que calidad y compromiso no están divorciados, sino que, por el contrario, se alimentan mutuamente (1997: 179-80).
\end{abstract}

\title{
5. Conclusión
}

Miguel Ángel Asturias, casi novela constituye el ensayo final de Cardoza y Aragón. En él plantea el escritor sus convicciones sobre problemas que lo habían preocupado desde sus ensayos y poemas iniciales publicados en Guatemala y París: la estética como esencia trascendente, el surrealismo, la identidad cultural. Y agrega otros más producto de su exilio y de su participación política: la crítica de artes plásticas, la revolución socialista, el mestizaje.

Tal como he planteado, existen dos grandes preocupaciones en el ensayo: la estética y la dimensión biográfica de Miguel Ángel Asturias. En cuanto a la primera, se asume la "obra como prodigio", inscribiéndose el autor en un esencialismo propio de los intelectuales de la ciudad letrada de la primera parte del siglo XX y valorando la vanguardia como modelo estético, en tanto canon de la modernidad. Siguiendo esta propuesta, la noción de crítica literaria que desarrolla el texto es igualmente esencialista: asume la crítica biográfica e incita a "crear una obra de arte" mediante la reflexión sobre otra "obra de arte", ignorando el desarrollo de la crítica literaria como disciplina. Esta concepción crítica impresionista es desarrollada en la aproximación a Asturias. Aquí el texto se dedica a efectuar suposiciones sobre la vida del autor, ignorando casi completamente la producción literaria del novelista y enfatizando en los "errores éticos" del biografiado. En esta narrativa de la automodelización y la censura, la propuesta estética cardociana de la contradicción (presentar luces y sombras) deviene en un sesgado intento por descalificar la trayectoria política de Asturias y defender la suya como metarrelato moralmente superior, en un momento histórico que veía desmoronarse paulatinamente las utopías.

\section{Notas}

1. Este texto es un ensayo crítico de la vida y la literatura de Miguel Ángel Asturias. Tiene dos ediciones: la primera, que utilizo en este trabajo, es: México: Ediciones Era, 1991. La segunda corresponde a: México: Costa-Amic, 1992. El ensayo está dividido en ocho capítulos subdivididos a su vez en apartados. Ni los capítulos ni sus secciones están titulados, solamente se distinguen los primeros con números 
romanos y los segundos, con numeración arábiga. No se trata de una biografía cronológica ni de un estudio sistemático de crítica literaria. Tampoco los capítulos desarrollan un solo tema. En todos ellos existen reflexiones que mezclan tres planos: el biográfico, el de crítica literaria y el político. Sin embargo, es posible destacar en el primero de ellos un énfasis por exponer los principios de una crítica impresionista y biográfica, la que sigue el autor en su acercamiento a Asturias. Esta crítica propone la necesidad del nivel biográfico para analizar el texto literario. A la vez, destaca que su interés se dedicará a la novela Hombres de maíz, juzgada como la única producción de alto valor por el crítico. También se puede observar un análisis de la literatura indigenista en el capítulo tercero. Aquí Cardoza plantea una fuerte crítica a una literatura que juzga imposible, porque no se puede acercar a la interioridad del mundo indígena. En el capítulo cuarto, se nota un énfasis en el estudio de la condición del indio, así como su inserción en la sociedad guatemalteca y sus relaciones con los otros grupos humanos que conforman la nación. Los otros capítulos, con excepción del octavo, que es una conclusión, se dedican a analizar la literatura y las dimensiones biográfica y política de Asturias. En el plano biográfico, Cardoza insiste en hacer evidentes las contradicciones de Miguel Ángel Asturias; fundamentalmente le reclama el haberse convertido en el símbolo del indigenismo guatemalteco y a la vez haber sido seguidor de los regímenes dictatoriales. En el plano de la crítica literaria, su preocupación es destacar Hombres de maíz. Finalmente, en el nivel político, analiza Cardoza la situación del maya en la sociedad de la década de los noventa y la problemática étnica de Guatemala. El texto toma, entonces, la figura vital, literaria y política de Asturias, pero a partir de ella elabora una reflexión sobre la identidad cultural guatemalteca, expresada en la discusión sobre la literatura indigenista, los problemas étnicos y el presente y el futuro de Guatemala.

2. Asegura Labastida que Cardoza "Supo que, en sus páginas más bellas, Asturias escribió en contra de sí mismo y que tuvo por norma suprema el cultivo de la palabra. Lo que rescata Cardoza, en Asturias, por encima de todo, es, precisamente, su pasión por el lenguaje. Hay aquí, pues, una lección de honradez intelectual: en los dos, en Asturias y en Cardoza" (1992: 65).

3. Consúltese su "Oda a Rubén Darío" en: Pol-lad'Ananta Katanta Paranta. Managua: Nueva Nicaragua, 1993: 95-99.

4. Véase "The Work of Art in the Age of Mechanical Reproduction" en: Illuminations: Essays and Reflections. New York: Schoken Books, 1968: 217-51.

5. Interpretando a García Canclini (1990: 281-322), en América Latina los efectos de la reproducción mecánica en la concepción del texto artístico se han hecho sentir al final del siglo XX con un cambio en la idea de "originalidad" que acentúa los fenómenos de hibridación cultural, la cual se presenta claramente en tres procesos: el descoleccionamiento, la desterritorialización de los procesos simbólicos y la expansión de los géneros impuros. El descoleccionamiento se refiere a la imposibilidad actual de explicar la cultura mediante la referencia a colecciones de bienes simbólicos, por ejemplo colecciones de arte culto y de folclor que a la vez que ordenaban los símbolos, los separaban y jerarquizaban. Hoy las culturas (cultas, populares o masivas) no se agrupan en conjuntos fijos o estables y, por consiguiente, no se reconoce la cultura elitista por referencia al conocimiento de las "grandes obras", o la cultura popular por los textos de etnias o comunidades cerradas. La desterritorialización de los procesos simbólicos tiene que ver con la pérdida de sentido del Estado nacional compacto, ya que se han modificado las fronteras entre centro y periferia. El ejemplo que para García Canclini es paradigmático es la ciudad mexicana fronteriza Tijuana, donde conviven dos culturas: la mexicana y la estadounidense. Por último, la expansión de los géneros impuros se relaciona con los cruces genéricos que efectúan las historietas y los grafitis, medios sincréticos y transculturales que borran los lugares tradicionales de enunciación y las fronteras entre los géneros discursivos.

6. Consúltese "De l'œuvre au texte" en: Essais critiques IV. Le brouissement de la langue. Paris: Éditions du Seuil, 1984: pp. 69-77. 
7. Véase el diálogo "Ion" en: Euvres complètes. Tome V, $1^{\text {re }}$ partie. Trad. Louis Méridier. Paris: Société d'édition Les Belles Lettres, 1931: 29-47.

8. García Canclini afirma que "una de las utopías más enérgicas y constantes de la cultura moderna, desde Galileo hasta las universidades contemporáneas, de los artistas del renacimiento hasta las vanguardias [fue]: construir espacios en que el saber y la creación puedan desplegarse con autonomía" (1990: 32).

9. Y prosigue el crítico: “a veces intentaron combinarla con otros movimientos de la modernidad -especialmente la renovación y la democratización. Sus desgarramientos, sus conflictivas relaciones con movimientos sociales y políticos, sus fracasos colectivos y personales, pueden ser leídos como manifestaciones exasperadas de las contradicciones entre los proyectos modernos" (1990: 42).

10. El texto inicia con un diálogo entre un pino y la nieve; luego el narrador apunta: "Entre la oreja y la lengua, el gran puente colgante temblaba con el paso fosforescente de los suicidas: un rumor de viento, que había sufrido mucho de las palabras, atravesaba, sin estela, el terso silencio liso, sinfonía muda y suspendida como la voz del cuerpo" (1992: 13).

11. Se lee en el poema XX: "El diccionario, espeso, manso, lerdo, mudo burdel sonoro casi disfrazado de objeto. Aíslas una hormiguita y otra, más ardiente que aquélla, hasta que en la llanura son una estrofa que comienza a fecundar copos de espacio, copos de tiempo, encrespándose como halcones, súbitamente tibias tórtolas, pechos de doncella sobre los que tiembla un alfanje inminente" (1989: 103).

12. En el cuarto poema de "Arte poética" se observa, igualmente, la fuerte presencia del surrealismo: "Mundo escrito con tinta simpática / corre por toda la alameda un álamo / loco vestigios del reloj de arena / la noche se disuelve en la lluvia / morena sombra canta rubio cuerpo / caracola sola del mar sonámbulo / por el escorpión violando a un lirio / la buganvilia relincha en el pájaro / abre el tiempo hara kiri otro espacio / abrilmente en invierno lo rescata / la lluvia que disuelve en la noche / tus marítimos muslos con su arpa / los amarillos frígidos gemidos / de una delicia hendida por la brisa / estamos solos / todapoderosa porque impotente / la muerte acaba de doblar la esquina / enredada en sus diáfanos monólogos / eternidad a todos cierto azar / el tiempo de los muertos quién lo mide / irreversible sólo es el futuro / de los vivos el tiempo el reloj vive" (1972: 12).

13. El poema que da inicio al texto continúa dentro de la misma poética: "Olivos dorándose en su aceite / Calor y olor de pan de boñiga / Burbuja en la punta de una aguja / Es la tarde antorcha desangrándose / Detenida por los geranios rojos / El canto de gallos y bramidos de toros / Hay una aura púrpura ternura / Bajo el alto azul acongojado / De mortaja y pañal / Y crepúsculo rauda que se asoma / Con rosados opacos pasos grises / Tartamudeando trémulo sus cosas" (1994: 7).

14. El texto plantea la "validez de la universalidad de lo fantástico" (1991: 68) y la trascendencia de la invención poética (69).

15. El enunciador cita como autoridad crítica la propuesta de Baudelaire: “'La crítica debe ser parcial, apasionada, política, es decir hacerse desde el punto de vista exclusivo, pero desde un punto de vista que abra la mayor cantidad de horizontes posibles', escribió Baudelaire" (1991: 21).

16. Dice el autor: "La obra habla por sí y no debiera necesitar explicación alguna. En realidad, no necesita comentario alguno. La crítica de arte entre más 'científica' se jacta de ser, nos parece como más alejada de su propósito, inmóvil en el centro mismo de su jactancia, ocupándose aún en todo aquello que es próximo a la naturaleza del arte, pero sin llegar a su naturaleza misma" (1944: 11).

17. Señala el enunciador: "Cada cosilla que escribimos es un puñado de luz o de sombra de ese misterio del yo profundo" (1991: 83). 
18. Para una contextualización de este modelo interpretativo véase: Wolfgang Kayser. Interpretación y análisis de la obra literaria. Trad. de María D. Mouton y V. García Yebra. 4ta. edición. Madrid: Gredos, 1968: 27-9.

19. Indica Dámaso Alonso en su Poesía española. Ensayo de métodos y límites estilísticos: "A ambos lados de la obra literaria hay dos intuiciones: la del autor y la del lector. La obra es registro, misterioso depósito de la primera, y dormido despertador de la segunda. La obra supone esas dos intuiciones, y no es perfecta sin ellas. Exagerando la dirección de nuestro concepto, diríamos que la obra principia sólo en el momento en que suscita la intuición del lector, porque sólo entonces comienza a ser operante" (1971: 38).

20. Señala el enunciador refiriéndose a Asturias: "Fue sibarita, toda su vida buscó la felicidad que no encontró sino en sus años juveniles de París" (1991: 148).

21. Dice el enunciador: "La discreción no fue su fuerte y confluían en él cualidades a veces antagónicas. Cuando en el éxito de Cien años de soledad se concentró la atención y la apartó de la novela continental, la lucidez le falla y acusa de plagio a García Márquez. Su contacto con la realidad se ostenta egoísta" (1991: 201).

22. Dice el enunciador nuevamente censurando y comparándose: "Su formación sociopolítica nunca fue más allá de la influencia recibida en París de Haya de la Torre y José Vasconcelos, colaboracionismo de clases, sin atención alguna a otros requerimientos. Fue nacionalista, fue antiimperialista. Concibe la libertad por medio de la cultura, y no tuvo curiosidad, como todos la tuvimos, de aproximarse a Freud, a Marx, e incluso enterarse muy superficialmente de Einstein. Pensaba como Vasconcelos que bastaba con la educación y con los 'libros redentores'” (1991: 184).

\section{Bibliografía}

Alonso, Dámaso. 1971. Poesía española. Ensayo de métodos y límites estilísticos. 5ta. edición. Madrid: Gredos.

Barthes, Roland. 1984. "De l' oeuvre au texte". Essais Critiques IV. Le brouissement de la langue. Paris: Éditions du Seuil: 69-77.

Benjamin, Walter. 1968. "The Work of Art in the Age of Mechanical Reproduction". Iluminations: Essays and Reflections. New York: Schoken Books: 217-251.

Cardoza y Aragón, Luis. 1924. Luna Park. París: Sainte-Catherine a Bruges. Prólogo de José Frías.

1926. Maelstrom. Films telescopiados. París: Editorial Excelsior. Prólogo de Ramón Gómez de la Serna.

1940. La nube y el reloj. México: Ediciones de la Universidad Nacional Autónoma.

1944. Apolo y Coatlicue. México: Ediciones La serpiente emplumada.

1955. Guatemala, las líneas de su mano. México: Fondo de Cultura Económica.

1972. Quinta Estación. Costa Rica: Editorial Universitaria Centroamericana. 
1986. El río, novelas de caballería. México: Fondo de Cultura Económica.

1988. Pintura contemporánea de México. México: Ediciones Era.

1989. Dibujos de ciego. Segunda edición. México: Siglo Veintiuno Editores.

1991. Miguel Ángel Asturias, casi novela. México: Ediciones Era.

1992. Pequeña sinfonía el Nuevo Mundo. Tercera edición. México: Fondo de Cultura Económica.

1992. Tierra de belleza convulsiva. México: Ediciones El Nacional.

1994. Lázaro. México: Ediciones Era.

Coronel Urtecho, José. 1993. Pol-lad'Ananta Katanta Paranta. Managua: Nueva Nicaragua.

Galich, Franz. 1995. “Miguel Ángel Asturias, casi novela de Luis Cardoza y Aragón. Estudio de una obra de Cardoza y Aragón sobre Asturias: la indigenidad de ambos". Revista Istmica. (2): 24-34.

García Canclini, Néstor. 1990. Culturas híbridas. Estrategias para entrar y salir de la modernidad. México: Editorial Grijalbo.

Huyssen, Andreas. 1998. "Vanguardia y postmodernidad. En busca de la tradición: Vanguardia y postmodernismo en los años 70". Trad. Antoni Torregrossa. Modernidad y Postmodernidad. Josep Picó (ed.). Madrid: Alianza Editorial: 141-164.

Kayser, Wolfgang. 1968. Interpretación y análisis de la obra literaria. Trad. María D. Mouton y V. García Yebra. 4ta. Edición. Madrid: Gredos.

Labastida, Jaime. 1992. "Luis Cardoza y Aragón, un hombre lleno de agonías”. Plural. 247 (abril): 64-64.

Liano, Dante. 1997. Visión crítica de la literatura guatemalteca. Guatemala: Editorial Universitaria. Universidad de San Carlos de Guatemala.

Méndez de Penedo, Lucrecia. 2001. Memorie controcorrente. 'El río. Novelas de caballería' di Luis Cardoza y Aragón. Roma: Bulzoni Editore.

Payeras, Mario. 1992. "Miguel Ángel Asturias, casi novela”. Revista de la Universidad de San Carlos (USAC). 18 (setiembre-diciembre): 57-60.

Platón. 1931. “Ion”. Oeuvres complètes. Tome V, $1^{\text {re }}$ partie. Trad. Louis Méridier. 